\title{
A Performance Analysis Model for the Training and Education of Information Security Talents
}

\author{
https://doi.org/10.3991/ijet.v15i05.13329 \\ Lin $\mathrm{Li}^{(\varpi)}$, Kai Zhang, Tao Li \\ Wuhan University of Science and Technology, Wuhan, China \\ Hubei Province Key Laboratory of Intelligent Information Processing and \\ Real-time Industrial System, Wuhan, China \\ lilin@wust.edu.cn
}

\begin{abstract}
There are many defects with the existing performance analysis system for the training and education (T\&E) of information security talents in Chinese colleges, ranging from the difficulty in transforming fuzzy information to the lack of objectivity. To overcome these defects, this paper develops an improved performance analysis model for the T\&E of information security talents. Firstly, the existing analysis strategies for the T\&E performance of information security talents were fully analyzed, and a performance analysis indicator system was established through the analysis. Based on the established indicator system, the gray classification and fuzzy information transformation were discussed for the performance analysis. On this basis, a grey clustering model for the T\&E of information security talents was constructed, and the realization of the corresponding algorithm was explained in details. The proposed model was proved feasible and effective through case analysis. In addition to theoretical innovation, our model also has a great potential in engineering, because the solving algorithm can effectively process fuzzy information with only a small sample set.
\end{abstract}

Keywords-Talent training, higher education, information security, performance analysis, decision model

\section{Introduction}

With the rapid development of science and technology in modern society, the application of information technology is becoming increasingly extensive, and information technology is playing a very important supporting role in many engineering fields [1-3]. However, with the continuous deepening of the application of information technology, information security issues have gradually become a research hotspot, many experts and scholars have carried out research on the information security technology and achieved a series of research results [4-6]. Moreover, as an effective means to provide support for the intensive research on information security technology, the T\&E of information security talents in colleges and universities is now receiving more attention from the society. This paper analyzes higher education from 
different perspectives, thereby providing a reference for the T\&E of information security talents [7-9].

Compared with other traditional disciplines, the T\&E of information security talents is a new subject which is closely related to the development of information technology. Therefore, to analyze the performance of T\&E modes of information security talents in colleges and universities, not only the setting of information security discipline should be taken into consideration, but also the ability of combining information security technology with scientific research should be considered as well, that is, the scientific practice needs to provide support for the cultivation of senior information security talents. At present, some scholars have discussed this issue from several perspectives. For example, Majed Rajab et al. have proposed a comprehensive theoretical model based on the Theory of Planned Behavior (TPB), the Protection Motivation Theory (PMT), the Theory of General Deterrence (TGD), and the Theory of Organization (TO); this model has been applied to predict the willingness of college employees to comply with information security policies [10]. Sherly Abraham et al. examined the influence of learners on the control of information security training effectiveness, and discussed the contents for formulating the training plans such as the required characteristics, the guiding principles, and the evaluation of effectiveness, etc. [11]. With social needs as the orientation, LI et al. explored a new type of cultivation mode for talents specialized in cyberspace security applications from the perspective of the integration of classroom teaching and faculty construction, practice course construction, and school-enterprise cooperative curriculum construction [12]. However, the systematic nature of these studies needs to be further improved; moreover, since the performance analysis of the T\&E of information security talents in colleges and universities involves many kinds of influencing factors, some factors can be analyzed quantitatively, some factors contain fuzzy information and need to be analyzed qualitatively, and the qualitative analysis needs to be transformed into quantitative analysis. From this, we can see that the performance analysis of the T\&E of information security talents in colleges and universities is the decision-making analysis of a system engineering project. At present, the research on system engineering decision analysis has many forms. There are system engineering studies based on the neural networks, for example, Tealab summarized the time series prediction systems based on artificial neural network (ANN) [13]; Ghosh et al. discussed a few common and uncommon methods of the input reconstruction of convolutional neural network $(\mathrm{CNN})$ [14]; Loesche used a neural network (NN) method to evaluate and analyze the degree of authenticity of gender differences in academic performance [15]. There are system engineering studies based on genetic algorithms (GA), for example, Grygar and Fabricius studied an efficient adjustment method of GA determined for the Pareto frontier [16]; Tseng et al. analyzed the application of block-based GA in disassembly sequence planning [17]; Xu et al. discussed the application of the random-crossover dynamic-mutation GA in the traveling salesman problem [18]; and there are system engineering studies based on AHP, for example, [19] Vázquez-Burgos et al. studied the fisheries water-quality management problem based on AHP [19]; Kursunoglu et al. used AHP to select the leaching method for calcium-magnesium laterite-nickel ore [20]; Rochikashvili and Bongaerts used AHP to discuss the multi-standard decision- 
making method for sustainable wall paints and coatings [21]. However, NN-based and GA-based system engineering analysis often require a large amount of sample data and have certain limitations on the processing of fuzzy information. Although AHPbased system engineering analysis can process fuzzy information, its subjectivity is relatively high and it is easy to miss the objectivity of the fuzzy information. To this end, based on existing research results, this paper applies the gray system theory [22$24]$, and proposes fuzzy performance analysis method for the T\&E of information security talents in colleges and universities, and gives analysis and explanation combining specific cases.

The content of this paper consists of five parts. The first part is an overview of the performance analysis of the T\&E of information security talents in colleges and universities, and it analyzes the development of related technologies. The second part discusses the strategies for implementing the T\&E of information security talents in colleges and universities, and a performance analysis system is constructed on this basis. The third part discusses performance analysis of the T\&E of information security talents in colleges and universities based on the grey system theory, and it gives the detailed implementation process. The fourth part adopts specific cases to verify and analyze the performance analysis of the $\mathrm{T} \& \mathrm{E}$ of information security talents in colleges and universities, and it gives corresponding analysis results. The fifth part is the conclusion.

\section{Strategies and Systems for the Performance Analysis of the T \& $\mathbf{E}$ of Information Security Talents in Colleges and Universities}

\subsection{Strategies for performance analysis}

The implementation purpose of modern higher education is to cultivate senior talents with professional qualities and can solve key engineering problems in practical applications, moreover, it also aims to cultivate senior talents with strong scientific research and innovation capabilities, thereby promoting the further development of professional field theories. It can be seen that the performance analysis of the T\&E of information security talents in colleges and universities needs to be conducted from three aspects.

Cultivation of professional quality: The information security major and the traditional majors have different requirements in the professional qualities during the talent cultivation and education. Traditional majors generally focus on the imparting of professional knowledge, for example, the mechanics major focuses on domain knowledge of mechanical engineering, the material major focuses on the domain knowledge of materials engineering, and the automation major focuses on domain knowledge of control engineering, etc. In contrast, the information security major is a brand-new major, it involves knowledges of multiple fields such as computer science, information engineering, network engineering, and information science; moreover, due to the rapid development of science and technology, the domain knowledge of the 
information security major is growing explosively; especially in the environment of big data, this trend is becoming increasingly obvious, resulting in that the information security problems have become more and more serious, and solving these problems has become an urgent need. Therefore, the cultivation and education of information security talents in colleges and universities not only requires the imparting of traditional professional knowledge, but also needs to keep pace with the times and closely follow the hot spots of science and technology in current society.

Cultivation of research ability: The research ability of students majored in information security is a very important measuring factor for the performance analysis of talent cultivation. Due to the explosive growth of information volume, information security has become a hot issue of scientific research in current society. Only by cultivating advanced talents with independent scientific research ability can we better adapt to the requirement of the development of modern society. Therefore, the T\&E of information security talents in colleges and universities can no longer rely solely on the traditional talent training model which is based on a single mode, but must adopt the composite method combining multiple modes to improve the scientific research ability of students. On the one hand, by providing students with scientific research projects with professional needs, especially projects that can combine with hot issues in current scientific research, key technical requirements and scientific problems to be solved should be proposed, so that students can understand the scientific problems to be studied. On the other hand, scientific research platforms, research supervisors and research interest groups should be provided to students through various forms and means, so that they can engage in the execution of the science projects.

Cultivation of innovation ability: As a key objective for the implementation of the TaE of information security talents in colleges and universities, innovation ability is one of the most important abilities for solving information security problems. Therefore, after the information security major is well planned, the professional courses of information security major are well set, and a research platform for the information security major is well established, we need to cultivate the innovation ability of information security talents. Innovation comes from practice and it's higher than the practice. Therefore, the innovation ability of information security talents needs to combine with the professional knowledge of the information security discipline, and emphasis must be laid on the integration of knowledge and practice, which requires to provide corresponding scientific research practical activities to examine and promote the students' innovation ability during the process of the implementation of the T\&E of information security talents in colleges and universities. For example, participating in national college student information technology innovation competitions, national college student entrepreneurial activities or similar science projects, or participating in information science related research projects jointly hold by colleges and universities, companies, research institutions, design institutes, or other organizations, can all play a positive role in enhancing the innovation ability of information security talents in the T\&E of information security talents in colleges and universities. 


\subsection{Performance analysis criteria and system construction}

Based on above analysis, to effectively conduct the performance analysis of the $\mathrm{T} \& \mathrm{E}$ of information security talents in colleges and universities, this paper selects professional qualities, research ability, and innovation ability as the corresponding performance analysis criteria. Under the guidance of these criteria, the performance analysis indicators under different criteria were selected.

Under the guidance of the professional quality cultivation criterion, the selection of performance analysis indicators focuses on improving the basic software and hardware teaching conditions of the information security major in colleges and universities, rationally setting up courses of information security major in colleges and universities, effectively utilizing the teaching resources of information security major in colleges and universities, enriching teaching methods of information security major in colleges and universities, and increasing expenditure of information security major in colleges and universities, etc., so as to improving the professional qualities of talents majored in information security in colleges and universities.

Under the guidance of the research ability cultivation criterion, the selection of performance analysis indicators focuses on improving the basic conditions of the research platform for the information security major in colleges and universities, rationally building a team of research talents for the information security major in colleges and universities, effectively utilizing the research results of information security major in colleges and universities, enhancing the academic communication ability of information security major in colleges and universities, increasing the number of published research papers and works and the number of research awards in the field of security information, so as to improve the research ability of talents majored in information security in colleges and universities.

Under the guidance of the innovation ability cultivation criterion, the selection of performance analysis indicators focuses on improving the basic conditions of the innovation platform of information security major in colleges and universities, rationally planning the innovation mechanism of information security major in colleges and universities, fully promoting the industry-university-research cooperation projects, increasing the degree of participation in scientific practical activities of the information security major in colleges and universities, enriching the scientific innovation achievements of the information security major in colleges and universities, so as to improve the innovation ability of talents majored in information security in colleges and universities.

As a result, the performance analysis system for the T\&E of information security major in colleges and universities is shown in Fig 1. 


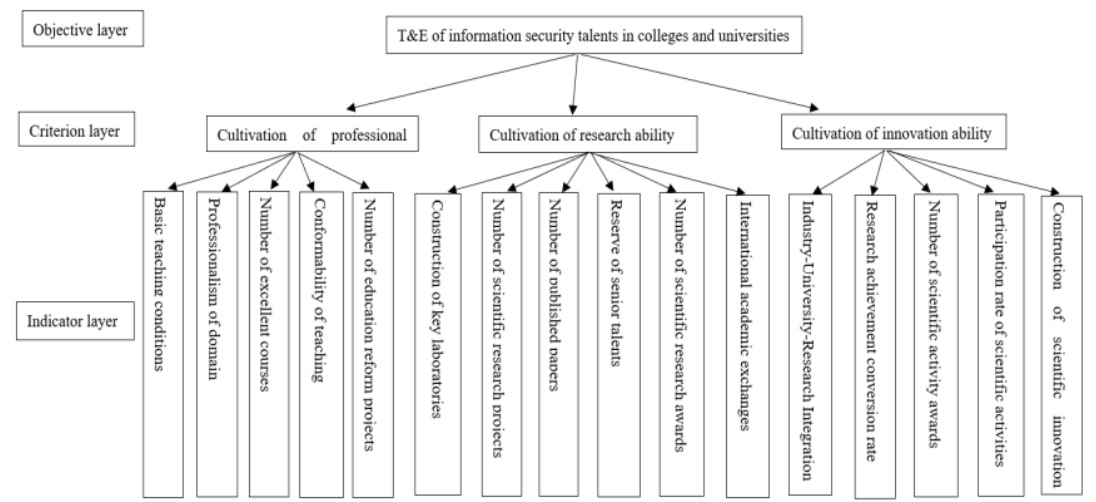

Fig. 1. Performance analysis system for the $T \& E$ of information security major in colleges and universities

\section{Grey Clustering Model for the Performance Analysis of the T\&E of Information Security Talents in Colleges and Universities}

\subsection{Grey category classification of performance analysis}

To effectively identify the effects of the T\&E of information security talents in colleges and universities and better support its performance analysis, the categories of the performance analysis need to be classified. The classification granularity of the performance analysis of the T\&E of information security talents in colleges and universities should be rational. Too large performance analysis granularity will lead to too many hierarchies in the performance analysis, especially when there are performance analysis indicators with fuzzy information, the processing ability of fuzzy information will be reduced, resulting in that the performance analysis indicators with fuzzy information could not be identified effectively; in extreme cases, each performance analysis indicator corresponds to a performance analysis category. Too small performance analysis granularity will lead to too few hierarchies in the performance analysis, resulting in that the performance analysis indicators could not be identified effectively, in extreme cases, all performance analysis indicators correspond only to one performance analysis category.

For this reason, based on above analysis, this paper divides the categories of the performance analysis of the T\&E of information security talents in colleges and universities into five hierarchies, namely poor (Gral), average (Gral2), good (Gral3), better (Gra4), excellent (Gra5). Since the grey system theory is applied to analyze it, the performance analysis categories are called the grey categories in this paper. Assuming that the value of the performance analysis indicator of the T\&E of information security talents in colleges and universities is $\mathrm{M}$, then for the i-th performance analysis indicator, its corresponding $\mathrm{j}$-th grey category model can be expressed as: 


$$
\left\{\begin{array}{l}
V_{o}^{j}=\left[v_{o}^{j}(a), v_{o}^{j}(b)\right] \\
V_{i}^{j}=\left[v_{i}^{j}(a), v_{i}^{j}(b)\right]
\end{array}\right.
$$

Where, ${ }^{j}$ represents the value interval of the j-th grey category; $v_{o}^{j}(a)$ is the maximum threshold corresponding to this category; $v_{o}^{j}(b)$ is the minimum threshold corresponding to this category; ${ }^{j}{ }^{j}$ represents the value interval of the j-th grey category corresponding to the i-th performance analysis indicator; $v_{i}^{j}(a)$ is the maximum value corresponding to this indicator; and $v_{i}^{j}(b)$ is the minimum value corresponding to this indicator.

\subsection{Fuzzy information transformation of performance analysis}

In order to have a unified performance analysis measurement standard for the T\&E of information security talents among different colleges and universities, it's necessary to transform the fuzzy information so that it has a unified analysis model with the accurate value information. From the above-mentioned performance analysis system for the T\&E of information security talents in colleges and universities, it can be seen that the magnitude of the fuzzy information can be expressed in two forms: the fuzzy interval form, and the fuzzy membership form.

If the performance analysis indicator of the $\mathrm{T} \& \mathrm{E}$ of information security talents in colleges and universities is shown in the form of fuzzy interval, that is $V_{i}^{j}=\left[v_{i}^{j}(a), v_{i}^{j}(b)\right], v_{i}^{j}(a)<v_{i}^{j}(b)$; then, when the indicator is a benefit-based performance analysis indicator, the transformed standardized value is:

$$
\left\{\begin{array}{l}
\overline{\bar{V}}_{i}^{j}=\left[\frac{v_{i}^{j}(a)-\min _{1 \leq i \leq M}\left[v_{i}^{j}(a), v_{i}^{j}(b)\right]}{\max _{1 \leq i \leq M}\left[v_{i}^{j}(a), v_{i}^{j}(b)\right]-\min _{1 \leqslant i \leq M}\left[v_{i}^{j}(a), v_{i}^{j}(b)\right]}, \frac{v_{i}^{j}(b)-\min _{\leq i \leq M}\left[v_{i}^{j}(a), v_{i}^{j}(b)\right]}{\operatorname{mix}_{\leq i \leq M}\left[v_{i}^{j}(a), v_{i}^{j}(b)\right]-\min _{1 \leq i \leq M}\left[v_{i}^{j}(a), v_{i}^{j}(b)\right]}\right] \\
\overline{\bar{V}}_{i}^{* j}=\frac{v_{i}^{j}(a)+v_{i}^{j}(b)-2 * \min _{1 \leq i \leq M}\left[v_{i}^{j}(a), v_{i}^{j}(b)\right]}{2 *\left(\max _{1 \leq i \leq M}\left[v_{i}^{j}(a), v_{i}^{j}(b)\right]-\min _{1 \leq i \leq M}\left[v_{i}^{j}(a), v_{i}^{j}(b)\right]\right)}
\end{array}\right.
$$

When it is a cost-based performance analysis indicator, the transformed standardized value is:

$$
\left\{\begin{array}{l}
\overline{\bar{V}}_{i}^{j}=\left[\frac{\max _{1 \leq i \leq M}\left[v_{i}^{j}(a), v_{i}^{j}(b)\right]-v_{i}^{j}(b)}{\max _{1 \leq i \leq M}\left[v_{i}^{j}(a), v_{i}^{j}(b)\right]-\min _{1 \leq i \leq M}\left[v_{i}^{j}(a), v_{i}^{j}(b)\right]}, \frac{\max _{1 \leq i \leq M}\left[v_{i}^{j}(a), v_{i}^{j}(b)\right]-v_{i}^{j}(a)}{\max _{1 \leq i}\left[v_{i}^{j}(a), v_{i}^{j}(b)\right]-\min _{1 \leq i \leq M}\left[v_{i}^{j}(a), v_{i}^{j}(b)\right]}\right] \\
\overline{\bar{V}}_{i}^{* j}=\frac{2 * \max _{1 \leq i \leq M}\left[v_{i}^{j}(a), v_{i}^{j}(b)\right]-v_{i}^{j}(b)-v_{i}^{j}(a)}{\left.2 * \max _{1 \leq i \leq M}\left[v_{i}^{j}(a), v_{i}^{j}(b)\right]-\min _{1 \leq i \leq M}\left[v_{i}^{j}(a), v_{i}^{j}(b)\right]\right)}
\end{array}\right.
$$


If the performance analysis indicator of the T\&E of information security talents in colleges and universities is shown in the form of fuzzy membership, that is $V_{i}^{j}=\varphi\left(V_{i}^{j}(x)\right)$; then, when it is a benefit-based performance analysis indicator, the transformed standardized value is:

$$
\overline{\bar{V}}_{i}^{* j}=V_{i}^{j}=\varphi\left(V_{i}^{j}(x)\right)
$$

When it is a cost-based performance analysis indicator, the transformed standardized value is:

$$
\overline{\bar{V}}_{i}^{* j}=1-V_{i}^{j}=1-\varphi\left(V_{i}^{j}(x)\right)
$$

In particular, the accurate value of the performance analysis indicator of the T\&E of information security talents in colleges and universities is a special form of fuzzy interval values, that is, when $v_{i}^{j}(a)=v_{i}^{j}(b), V_{i}^{j}=\left[v_{i}^{j}(a), v_{i}^{j}(b)\right]$ becomes a point value information, so the above formulas (2) and (3) are converted to:

$$
\begin{aligned}
& {\overline{V_{i}}}^{* j}=\frac{V_{i}^{j}-\min _{1 \leq i \leq M} V_{i}^{j}}{\max _{1 \leq i \leq M} V_{i}^{j}-\min _{1 \leq i \leq M} V_{i}^{j}} \\
& {\overline{V_{i}}}^{* j}=\frac{\max _{1 \leq i \leq M} V_{i}^{j}-V_{i}^{j}}{\max _{1 \leq i \leq M} V_{i}^{j}-\min _{1 \leq i \leq M} V_{i}^{j}}
\end{aligned}
$$

\subsection{Construction of grey clustering model of performance analysis}

According to the gray clustering analysis method $[25,26]$, the whitening weight function is adopted to construct the grey clustering model for the performance analysis of the T\&E of information security talents in colleges and universities. Based on above-proposed grey categories of the $\mathrm{T} \& \mathrm{E}$ of information security talents in colleges and universities, its whitening weight functions can be established in three forms.

The gray category Gral is the first form, as shown in Fig 2.

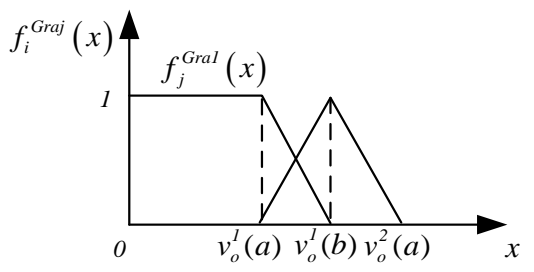

Fig. 2. Whitening weight function of gray category Gral 
The corresponding mathematical model is expressed as:

$$
f_{i}^{\text {Gral }}(x)= \begin{cases}0 & x \notin\left[0, v_{o}^{l}(b)\right] \\ \frac{v_{o}^{l}(b)-x}{v_{o}^{l}(b)-v_{o}^{l}(a)} & x \in\left[v_{o}^{l}(a), v_{o}^{l}(b)\right] \\ 1 & x \in\left[0, v_{o}^{l}(a)\right]\end{cases}
$$

The gray categories Gra2, Gra3 and Gra4 are the second form, as shown in Fig 3.

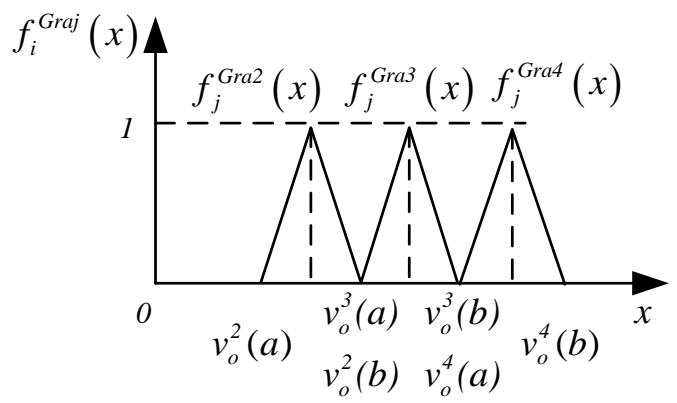

Fig. 3. Whitening weight functions of gray categories Gra2, Gra3and Gra4

The corresponding mathematical model is expressed as:

$$
\begin{aligned}
& \int \frac{2 *\left(x-v_{o}^{2}(a)\right)}{v_{o}^{2}(b)-v_{o}^{2}(a)} \quad x \in\left[v_{o}^{2}(a), \frac{v_{o}^{2}(a)+v_{o}^{2}(b)}{2}\right] \\
& f_{i}^{G r a 2}(x)= \begin{cases}0 & x \notin\left[v_{o}^{2}(a), v_{o}^{2}(b)\right]\end{cases} \\
& \frac{2 *\left(v_{o}^{2}(b)-x\right)}{v_{o}^{2}(b)-v_{o}^{2}(a)} \quad x \in\left[\frac{v_{o}^{2}(a)+v_{o}^{2}(b)}{2}, v_{o}^{2}(b)\right] \\
& \int \frac{2 *\left(x-v_{o}^{3}(a)\right)}{v_{o}^{3}(b)-v_{o}^{3}(a)} \quad x \in\left[v_{o}^{3}(a), \frac{v_{o}^{3}(a)+v_{o}^{3}(b)}{2}\right]
\end{aligned}
$$

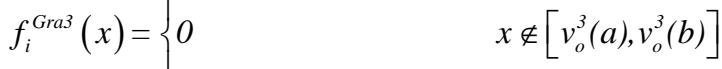

$$
\begin{aligned}
& \frac{2 *\left(v_{o}^{3}(b)-x\right)}{v_{o}^{3}(b)-v_{o}^{3}(a)} \quad x \in\left[\frac{v_{o}^{3}(a)+v_{o}^{3}(b)}{2}, v_{o}^{3}(b)\right]
\end{aligned}
$$




$$
f_{i}^{\text {Grat }}(x)=\left\{\begin{array}{lc}
\frac{2 *\left(x-v_{o}^{4}(a)\right)}{v_{o}^{4}(b)-v_{o}^{4}(a)} & x \in\left[v_{o}^{4}(a), \frac{v_{o}^{4}(a)+v_{o}^{4}(b)}{2}\right] \\
0 & x \notin\left[v_{o}^{4}(a), v_{o}^{4}(b)\right] \\
\frac{2 *\left(v_{o}^{4}(b)-x\right)}{v_{o}^{4}(b)-v_{o}^{4}(a)} & x \in\left[\frac{v_{o}^{4}(a)+v_{o}^{4}(b)}{2}, v_{o}^{4}(b)\right]
\end{array}\right.
$$

The gray category $G r a 5$ is the third form, as shown in Fig 4.

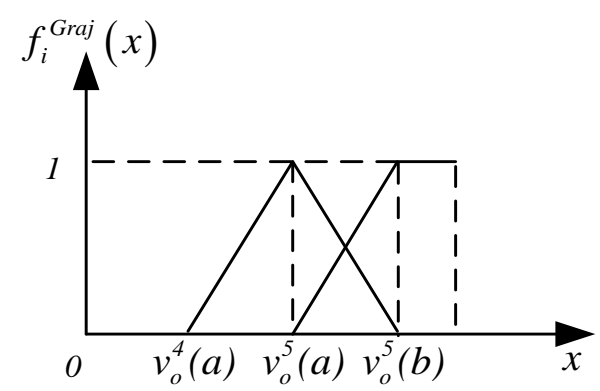

Fig. 4. Whitening weight function of gray category Gra5

The corresponding mathematical model is expressed as:

$$
f_{i}^{\text {Gras }}(x)=\left\{\begin{array}{lc}
0 & x \notin\left[0, v_{o}^{5}(a)\right] \\
\frac{x-v_{o}^{5}(a)}{v_{o}^{5}(b)-v_{o}^{5}(a)} & x \in\left[v_{o}^{5}(a), v_{o}^{5}(b)\right] \\
1 & x \in\left[v_{o}^{5}(b), 1\right]
\end{array}\right.
$$

\subsection{Performance analysis model and algorithm implementation}

Assuming that after standardization, the obtained value of the $\mathrm{i}$-th performance analysis indicator of the performance analysis object of the T\&E of information security talents in colleges and universities is $\bar{V}_{i}^{*}$, then based on the above-mentioned whitening weight function, it can be obtained that its whitening weight coefficient with respect to the $\mathrm{j}$-th grey category is $f_{i}^{\text {Graj }}(x)$; if the weight of the $\mathrm{i}$-th performance analysis indicator is wi, the gray clustering fitness of the object of the performance analysis of the $\mathrm{T} \& \mathrm{E}$ of information security talents in colleges and universities with respect to all performance analysis indicators and the i-th gray category is expressed as: 


$$
\phi^{G r a j}=\sum_{i=1}^{M}\left(w_{i} * f_{i}^{G r a j}(x)\right)
$$

In particular, if the performance analysis indicators have the same weight, the averaging weight process could be adopted, and the above formula could be transformed to:

$$
\phi^{\text {Graj }}=\sum_{i=1}^{M}\left(\frac{1}{M} * f_{i}^{G r a j}(x)\right)
$$

According to the principles of performance analysis of the T\&E of information security talents in colleges and universities, if the following formula could be satisfied:

$$
\phi^{*}=\phi^{\text {Grak }}=\max _{1 \leq j \leq N}\left(\phi^{\text {Graj }}\right), 1 \leq k \leq N
$$

Then, it means that this object of the performance analysis of the T\&E of information security talents in colleges and universities belongs to the k-th grey category.

Therefore, according to the above discussion, it can be seen that the implementation process of the performance analysis of the T\&E of information security talents in colleges and universities is shown as Fig 5.

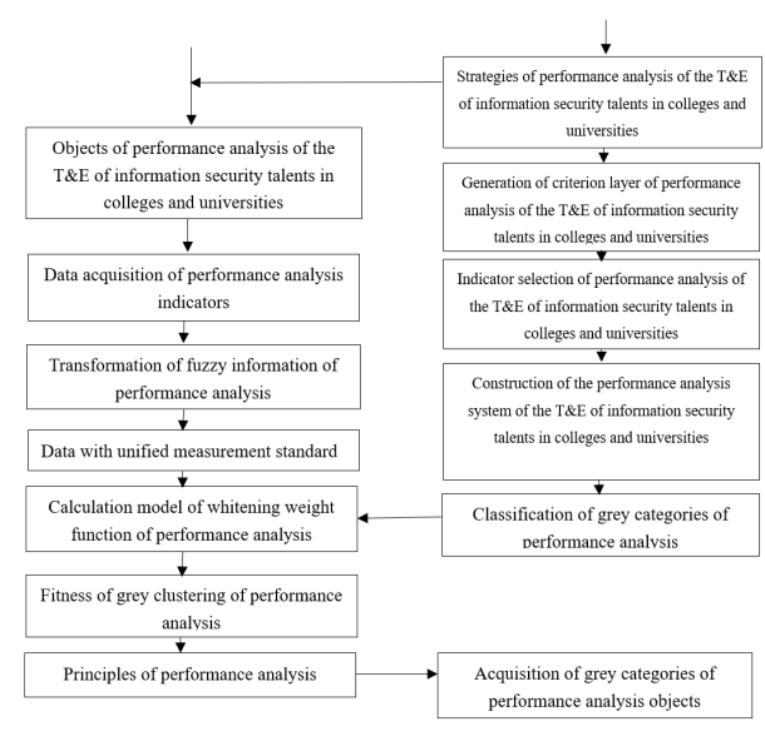

Fig. 5. Flowchart for the performance analysis system of the T\&E of information security talents in colleges and universities 


\section{Case Analysis}

In order to better illustrate the feasibility and effectiveness of the performance analysis model for the T\&E of information security talents in colleges and universities established in this paper, the following paragraphs take the evaluation of the T\&E of information security talents in a certain college as the example, based on expert opinions and field investigations, the value intervals of the five grey categories of the performance analysis of the T\&E of information security talents in the college respectively are: $V(\mathrm{Gral})=[0,0.65], \quad V(\mathrm{Gra} 2)=[0.55,0.75], \quad V(\mathrm{Gra3})=[0.65,0.85]$ $V(\operatorname{Gra} 4)=[0.75,0.95]$, and $V(\operatorname{Gra})=[0.85,1.0]$.

Combining questionnaire survey and data statistics, the original data of the performance analysis objects was obtained, the types of the performance analysis indicators were subject to the fuzzy information transformation, and the values of the performance analysis were obtained as shown in Table 1.

Table 1. Values of the performance analysis of the T\&E of information security talents

\begin{tabular}{|c|c|c|c|c|}
\hline Criterion layer & Indicator layer & $\begin{array}{c}\begin{array}{c}\text { Original } \\
\text { value }\end{array} \\
\end{array}$ & $\begin{array}{c}\text { Transformed } \\
\text { value }\end{array}$ & $\begin{array}{c}\text { Extreme } \\
\text { value }\end{array}$ \\
\hline \multirow{5}{*}{$\begin{array}{l}\text { Cultivation of } \\
\text { professional } \\
\text { quality }\end{array}$} & Basic teaching conditions & $80-90$ & 0.85 & $0-100$ \\
\hline & Professionalism of domain knowledge & $90-95$ & 0.925 & $0-100$ \\
\hline & Number of excellent courses & 7 & 0.70 & $\geq 10$ \\
\hline & Conformability of teaching & $90-95$ & 0.925 & $0-100$ \\
\hline & Number of education reform projects & 4 & 0.667 & $\geq 6$ \\
\hline \multirow{6}{*}{$\begin{array}{l}\text { Cultivation of } \\
\text { research ability }\end{array}$} & Construction of key laboratories & $75-85$ & 0.80 & $0-100$ \\
\hline & Number of scientific research projects & 15 & 0.75 & $\geq 20$ \\
\hline & Number of published papers & 216 & 1.000 & $\geq 200$ \\
\hline & Reserve of senior talents & $80-90$ & 0.85 & $0-100$ \\
\hline & Number of scientific research awards & 6 & 0.60 & $\geq 10$ \\
\hline & International academic exchanges & 26 & 0.867 & $\geq 30$ \\
\hline \multirow{5}{*}{$\begin{array}{l}\text { Cultivation of } \\
\text { innovation } \\
\text { ability }\end{array}$} & Industry-University-Research Integration & $70-80$ & 0.75 & $0-100$ \\
\hline & Research achievement conversion rate & 0.65 & 0.65 & $0-1$ \\
\hline & Number of scientific activity awards & 4 & 0.80 & $\geq 5$ \\
\hline & Participation rate of scientific activities & 0.56 & 0.56 & $0-1$ \\
\hline & Construction of scientific innovation platform & $65-75$ & 0.675 & $0-100$ \\
\hline
\end{tabular}

According to the calculation model of the whitening weight functions of each gray category given in the paper, the clustering coefficients between each performance analysis indicator and different gray categories were obtained. The results are shown in Table 2. 
Table 2. Calculation results of clustering coefficients

\begin{tabular}{|l|c|c|c|c|c|}
\hline \multicolumn{1}{|c|}{ Performance indicators } & Gra1 & Gra2 & Gra3 & Gra4 & Gra5 \\
\hline Basic teaching conditions & 0 & 0 & 0 & 1.000 & 0 \\
\hline Professionalism of domain knowledge & 0 & 0 & 0 & 0.25 & 0.75 \\
\hline Number of excellent courses & 0 & 0.500 & 0.500 & 0 & 0 \\
\hline Conformability of teaching & 0 & 0 & 0 & 0.25 & 0.75 \\
\hline Number of education reform projects & 0 & 0.830 & 0.170 & 0 & 0 \\
\hline Construction of key laboratories & 0 & 0 & 0.500 & 0.500 & 0 \\
\hline Number of scientific research projects & 0 & 0 & 1.000 & 0 & 0 \\
\hline Number of published papers & 0 & 0 & 0 & 0 & 1.000 \\
\hline Reserve of senior talents & 0 & 0 & 0 & 1.000 & 0 \\
\hline Number of scientific research awards & 0.500 & 0.500 & 0 & 0 & 0 \\
\hline International academic exchanges & 0 & 0 & 0 & 0.830 & 0.170 \\
\hline Industry-University-Research Integration & 0 & 0 & 1.000 & 0 & 0 \\
\hline Research achievement conversion rate & 0 & 1.000 & 0 & 0 & 0 \\
\hline Number of scientific activity awards & 0 & 0 & 0.500 & 0.500 & 0 \\
\hline Participation rate of scientific activities & 0.900 & 0.100 & 0 & 0 & 0 \\
\hline Construction of scientific innovation platform & 0 & 0.750 & 0.250 & 0 & 0 \\
\hline
\end{tabular}

Above data was subject to the averaging weight process, and the obtained clustering fitness degree of the performance analysis object and the different grey categories respectively were $0.088,0.230,0.245,0.271$, and 0.167 . According to the principles of performance analysis, the gray category of the performance analysis object was Gra4. From the calculation results, it can be seen that the clustering fitness degrees of the performance analysis object with respect to different grey categories were quite distinct, indicating good distinguishability.

\section{Conclusion}

The performance analysis of the T\&E of the information security talents in colleges and universities is a complex systematic decision-making analysis project, which needs to process the performance information with multiple hierarchies, factors, types, and uncertain characteristics. By constructing a performance analysis system, classifying grey categories, establishing performance analysis grey clustering model and giving key content such as algorithm implementation processes, the model proposed in this paper had effectively dealt with problems in the process of performance analysis of the T\&E of information security talents in colleges and universities, and the application results had shown that the model proposed in the paper had good adaptability. At the same time, the performance analysis model of the T\&E of information security talents in colleges and universities proposed in this paper is also of important reference significance for other engineering decision analysis with similar characteristics, and it can provide support for complex systematic decision-making problems. 


\section{Acknowledgement}

The research work was supported by the National Natural Science Foundation of China (Grant Nos. 61702383, 61602350), Scientific research project of Hubei Provincial Department of Education (B2018554).

\section{$7 \quad$ References}

[1] Saeidi, P., Saeidi, S. P., Sofian, S., Saeidi, S. P., Nilashi, M., Mardani, A. (2019). The impact of enterprise risk management on competitive advantage by moderating role of information technology. Computer Standards \& Interfaces, 63: 67-82. https://doi.org/10.10 $\underline{16 / j . c s i .2018 .11 .009}$

[2] Melián-Alzola, L., Fernández-Monroy, M., Hidalgo-Peñate, M. (2020). Information technology capability and organisational agility: A study in the Canary Islands hotel industry. Tourism Management Perspectives, 33: 1-9. https://doi.org/10.1016/j.tmp.2019. $\underline{100606}$

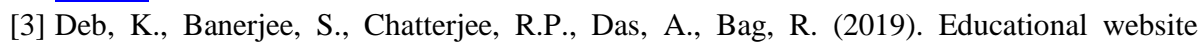
ranking using fuzzy logic and k-means clustering based hybrid method. Ingénierie des Systèmes d'Information, 24: 497-506.https://doi.org/10.18280/isi.240506

[4] Angraini, Alias, R. A., Okfalisa. (2019). Information Security Policy Compliance: Systematic Literature Review. Procedia Computer Science, 161: 1216-1224. https://doi. org/10.1016/j.procs.2019.11.235

[5] Haqaf, H., Koyuncu, M. (2018). Understanding key skills for information security managers. International Journal of Information Management, 43: 165-172. https://doi.org/ 10.1016/j.ijinfomgt.2018.07.013

[6] Melamed, T. (2018). An active man-in-the-middle attack on bluetooth smart devices. International Journal of Safety and Security Engineering, 8(2), 200-211. https://doi.org/10. 2495/safe-v8-n2-200-211

[7] Jacobs, R. J., Caballero, J., Parmar, J., Kane, M. N. (2019). The role of self-efficacy, flexibility, and gender in pharmacy students' health information technology readiness. Currents in Pharmacy Teaching and Learning, 11(11): 1103-1110. https://doi.org/10.101 6/j.cptl.2019.07.016

[8] Bongiovanni, I. (2019). The least secure places in the universe? A systematic literature review on information security management in higher education. Computers \& Security, 86: 350-357. https://doi.org/10.1016/j.cose.2019.07.003

[9] Cao, T. J., Guo, Y. (2019). Teaching research and practice of new information security technology under the background of professional accreditation . China Modern Educational Equipmentn, (11): 76-79.

[10] Rajab, M., Eydgahi, A. (2019). Evaluating the explanatory power of theoretical frameworks on intention to comply with information security policies in higher education. Computers \& Security, 8: 211-223. https://doi.org/10.1016/j.cose.2018.09.016

[11] Abraham, S., Chengalur-Smith, I. (2019). Evaluating the effectiveness of learnercontrolled information security training. Computers \& Security, 87: 1-12. https://doi.org/ $\underline{10.1016 / j . \operatorname{cose} .2019 .101586}$

[12] Li, P. P., Zhu, R., Du, X., Yu, H. N., Miao, C. Y. (2019). Sustainable competitiveness of Cyberspace Security application-oriented personnel training model. Computer Education, (10): 121-124. 
[13] Tealab, A. (2018). Time series forecasting using artificial neural networks methodologies: A systematic review. Future Computing and Informatics Journal, 3(2): 334-340. https://do i.org/10.1016/j.fcij.2018.10.003

[14] Ghosh, S., Das, N., Nasipuri, M. (2019). Reshaping inputs for convolutional neural network: Some common and uncommon methods. Pattern Recognition, 93: 79-94. https:// doi.org/10.1016/j.patcog.2019.04.009

[15] Loesche, P. M. (2019). Estimating the true extent of gender differences in scholastic achievement: A neural network approach. Intelligence, 77: 1-9. https://doi.org/10.1016/j.in $\underline{\text { tell.2019.101398 }}$

[16] Grygar, D., Fabricius, R. (2019). An Efficient Adjustment of Genetic Algorithm for Pareto Front Determination. Transportation Research Procedia, 40: 1335-1342. https://doi.org/10. 1016/j.trpro.2019.07.185

[17] Tseng, H. F., Chang, C. C., Lee, S. C., Huang, Y. M. (2018). A Block-based genetic algorithm for disassembly sequence planning. Expert Systems with Applications, 96: 492505. https://doi.org/10.1016/j.eswa.2017.11.004

[18] Xu, J., Pei, L., Zhu, R. Z. (2018). Application of a Genetic Algorithm with Random Crossover and Dynamic Mutation on the Travelling Salesman Problem. Procedia Computer Science, 131: 937-945. https://doi.org/10.1016/j.procs.2018.04.230

[19] Vázquez-Burgos, J. V., Carbajal-Hernández, J. J., Sánchez-Fernández, L. P., MorenoArmendáriz, M. A., Tello-Ballinas, J. A., Hernández-Bautistac, I. (2019). An Analytical Hierarchy Process to manage water quality in white fish (Chirostoma estor estor) intensive culture. Computers and Electronics in Agriculture, 167: 1-10. https://doi.org/10.1016/j.com pag.2019.105071

[20] Kursunoglu, S., Tanlega Ichlas, Z., Kaya, M. (2017). Leaching method selection for Caldag lateritic nickel ore by the analytic hierarchy process (AHP). Hydrometallurgy, 171: 179-184. https://doi.org/10.1016/j.hydromet.2017.05.013

[21] Rochikashvili, M., Bongaerts, J. C. (2016). Multi-criteria Decision-making for Sustainable Wall Paints and Coatings Using Analytic Hierarchy Process. Energy Procedia, 96: 923933. https://doi.org/10.1016/j.egypro.2016.09.167

[22] Bezuglov, A., Comert, G. (2016). Short-term freeway traffic parameter prediction: Application of grey system theory models. Expert Systems with Applications, 62: 284292. https://doi.org/10.1016/j.eswa.2016.06.032

[23] Wu, W. H., Lin, C. T., Peng, K, H., Huang, C. C. (2012). Applying hierarchical grey relation clustering analysis to geographical information systems - A case study of the hospitals in Taipei City. Expert Systems with Applications, 39(8): 7247-7254. https://doi. org/10.1016/j.eswa.2012.01.052

[24] Karakoç, O., Avni Es, H., Fırat, S. U. (2019). Evaluation of the development level of provinces by grey cluster analysis. Procedia Computer Science, 158: 135-144. https://doi. org/10.1016/j.procs.2019.09.036

[25] Wu, H. Y. (2019). A Fuzzy Evaluation Model of Software Project Performance Based on Grey Cluster Analysis. Journal of Southwest China Normal University (Natural Science Edition), 44(9), 68-75.

[26] Rajesh, R. (2018). Measuring the barriers to resilience in manufacturing supply chains using Grey Clustering and VIKOR approaches. Technology in Society, 126: 259-273. https ://doi.org/10.1016/j.measurement.2018.05.043 


\section{Authors}

Lin Li, received the B.S. degree in computer science and technology, the M.S. degree in computer application, the Ph.D. degree in computer software and theory from Wuhan University of Science and Technology and Wuhan University. Her research interests include Information Security, Artificial Intelligence, deep learning and software engineering.

Kai Zhang, received the Ph.D. degree in system analyses and integrate from Huaz hong University of Science and Technology.His research focuses on evolutionary co mputation and multi-criteria decision making.

Tao Li, received the B.S. degree in computer science and technology, the M.S. degree in computer application, the Ph.D. degree in Computer architecture from Wuhan University. His research interests include Information Security, Artificial Intelligence.

Article submitted 2019-07-28. Resubmitted 2019-11-19. Final acceptance 2019-11-23. Final version published as submitted by the authors. 